\title{
Problems of Modeling Macroeconomic Indicators in the Conditions of Instability of Impacts on the Ecosystem
}

\author{
Nikolai T. Katanaev 1[ORCID 0000-0001-5099-737X], \\ Elena E. Alenina ${ }^{*}$ [ORCID 0000-0002-0109-3064], \\ Vera V. Ziulina 1[ORCID 0000-0002-9419-1121], \\ Ilya A. Alenin 1[ORCID 0000-0002-7373-2419], \\ Mikhail A. Lastovsky 1[ORCID 0000-0003-1262-8332]
}

\author{
${ }^{1}$ Moscow Polytechnic University, Moscow, Russia \\ e-alenina@mail.ru
}

\begin{abstract}
The paper provides an assessment of the state of economic theory and the possibility of its use in the mathematical description of macroeconomic processes in order to analyze and synthesize the management system of economic objects that are quasi-static in nature with a difficult to formalize pattern of slowly changing economic indicators, which was used as GDP. An analysis is given of the reasons that cause difficulties in identifying this indicator in a long period of time due to random internal and external influences on the object under study. The article describes a methodology and a computational experiment associated with modeling GDP statistics in the range from 1998 to 2020 in the classes of functions: exponential, logarithmic, exponential, and polynomial. The results are obtained in the form of aperiodic trends that do not reflect changes in GDP indicators during the crisis and economic recession. The study of the possibility of using the GDP model in the procedure for extrapolating (forecasting) analytical results until 2023 also led to a negative result. The conducted studies have shown an urgent need to create dynamic models with functional and statistical links, which make it possible to identify the influence of external and internal influences on an economic object.
\end{abstract}

Keywords: economic theory, cycles, identification, monetization, dynamics, factors, models, functions, interpolation, crisis, forecast

\section{INTRODUCTION}

The imperfection of theoretical developments in the economy gives rise to an urgent problem directly related to the solution of the most important national economic task, aimed at carrying out in-depth analysis and synthesis of the management system in order to forecast and find an effective way of the country's economic development. In the absence of an adequate analytical research apparatus in economic theory, it is unlikely to expect the emergence of models that could reproduce the studied business processes with a high degree of adequacy.

Let us note important, from our point of view, aspects related to the crisis state of economic theory, which reduce the practical significance of business process models. If the theory of research of technical systems has been successfully developing for several centuries, then in economics science in a really functioning macrosystem has acquired a sluggish character.

First of all, this can be explained with the fact that effective management levers are mainly concentrated in the hands of the global financial system, which in its personal interests is not interested in promoting scientific research aimed at developing optimal strategies for the development of the entire human society. Since Russia is imposed on the fate of the raw material appendage of developed 
countries, the prospect of developing an effective economic theory is hardly fully feasible if the strategic direction of economic development is not adjusted to the real sector of the economy [1].

An objective factor associated with the nature of the processes occurring in the objects under study is also important. Descriptions of the dynamics of processes in technical systems are usually based on the known laws of motion of solids, as well as on the laws of hydrodynamics, thermodynamics, gas dynamics, electrical laws, etc. Measurement systems and standards are prescribed for them. All this, in the presence of high-performance computing technology, makes it possible to successfully conduct research in the time and frequency domains in order to obtain information about the degree of stability, controllability, observability of systems, as well as to carry out procedures for finding the optimal parameters of the system and the control laws of the objects under study. In the economy, especially in its real sector, the dynamics of processes is extended in time and is predominantly quasi-static in nature. For example, statistical information on GDP can be obtained at the end of a calendar year and at the end of each quarter; therefore, it is very difficult to obtain an equation for the dynamics of the process and assess the controllability and stability of the economic system as is customary in technical systems. This is especially true of the theory of long, medium and short waves, widely discussed in the scientific community [2-5], whose history goes back at least 100 years.

In the work [2] N.D. Kondratyev presented data based on the observation of a number of economic factors in the long term, where he noted the cyclical nature of the process, when the growth phase passes into a recession phase with a period of 50 years. Although D.I. Oparin [3], while studying the nature of deviations from the average value of the studied patterns, did not reveal a strict cyclical nature of the process.

The popularity of N.D. Kondratyev was created by J. Schumpeter [4]. He introduced the term "Kondratieff waves" (K-waves or K-cycles), in which periodic cycles represent a series of alternating ups and downs of indicators of the level of development of the world economy with a duration of 48-55 years. These scientific developments have become widespread in the field of modeling various wavelengths (long, medium, short), among which we will mention only a few of them. The importance of the development of the theory of long waves (TDW) was successfully formulated by S.Yu. Glazyev [5]: “... the development of a common TDV will simultaneously be a fundamental contribution to the theory of longterm economic development, which has not yet been created".

\section{MATERIALS AND METHODS}

Research in the field of K-wave modeling has generated widespread interest in the scientific world, as evidenced by the huge number of presentations posted on the Internet. In Figure 1 it is shown the most typical from the point of view of the approach to the study of macroeconomic indicators and the dynamics of phenomena, a fragment of the graphic image of long waves, which is used here only as illustrative material.

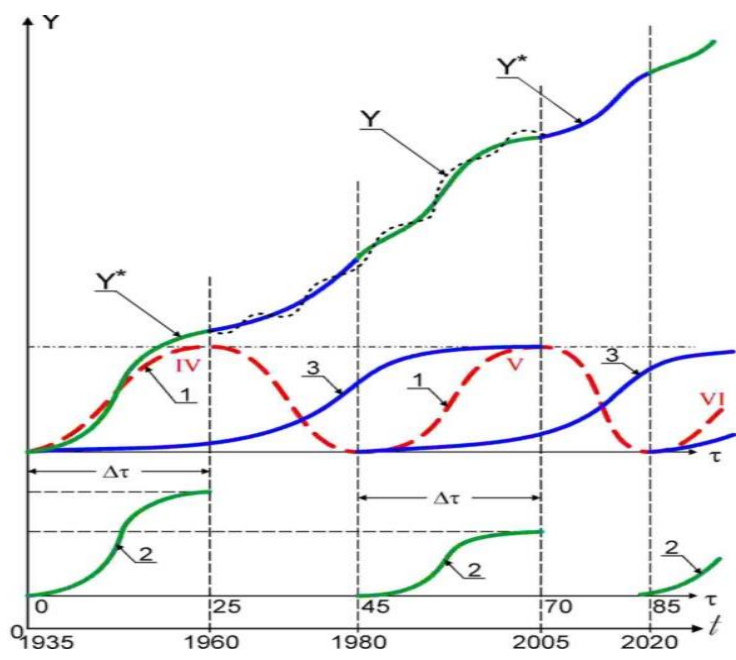

Figure 1. Release trajectory Y (GDP): 1 Kondratyev's cycles; 2 - trajectories of diffusion of innovative products to markets; 3 - infratrajectories

Source: Pictures of the Internet

Without entering into a discussion on the content of the components of the graph, we note the main thing - the absence of a subject of discussion, which usually should be represented on the ordinate axis in a certain scale with an indication of the dimension. Only in this case, studies acquire a substantive character, which makes it possible to judge the practical significance of the processes under study. This fact is typical for the vast majority of presentations. In Figure 1 it is only proposed to use GDP as a factor under study as the main indicator of the level of development of the research object.

This situation, unfortunately, is forced. The researcher usually understands that the choice of GDP as the main indicator of the studied economic 
processes is associated with the need to take into account external and internal factors affecting its absolute value, namely: the method of calculating GDP (in fixed or in current prices), the volume of money supply in the country, inflation rate, ongoing reforms, etc. On the other hand, it is necessary to take into account the share of a large number of innovative products in the formation of GDP.

Of course, you can take the statistics from Rosstat. In this case, Rosstat is responsible for the reliability of the results of calculating the GDP, but at the same time there is still a need to solve the most complex problem associated with the integration of the shares of innovative products [6].

Within the framework of the theory of large waves, the studied indicator can be taken, for example, the production of tractors, cars, nonferrous metals, steel structures, etc. The model can be based on the well-known production function, in which the gross product is considered as a function of three main factors: labor, capital, resources. In this case, in the financial indicators of the activities of economic entities, we can find the following characteristics: labor productivity, capital productivity, resource productivity and their inverse indicators: labor intensity, capital intensity, resource intensity. However, such indicators are valid only if all three factors are independent of each other and are determined with expanding the production function in a Taylor or Maclaurin series. The partial derivatives of this function are just the above indicators.

A similar situation is possible, for example, with a successfully functioning planned economy, fully provided with the resources of all three factors. The real state of the economy in Russia is such that over the past 30 years, the level of monetization has varied within the range of $0.125-0.5$, while for a favorable development of the real sector of the economy, this level should not be lower, at least 0.75 .

An organic shortage of financial resources leads to the fact that all factors of the production function become interdependent, and primarily on the money supply in the economy. Ultimately, this leads to a sharp drop in the production of the real gross product. While controlling the level of the money supply, one can effectively influence the state of the economy as a whole, leading it to a crisis state or to a positive dynamic of macroeconomic indicators [7, 8]. At any level of development of economic theory, the dominant still remains the adopted strategy of economic development, which should radically affect the structure and content of models of macroeconomic systems.

Ways to solve the above problems are at the stage of development; therefore, the effectiveness and practical significance of the existing theories are still at a very low level.

\section{RESULTS}

As for the collapse of traditional business models, for an objective analysis of this thesis, we will conduct a computational experiment with GDP, using models built on the basis of various wellknown classes of functions. The purpose of these studies is precisely the possibility of creating mathematical models with a high degree of adequacy to real GDP statistics obtained by Rosstat (Table 1) in a wide time interval.

The relevance and importance of setting up such an experiment is associated not only with scientific and practical research, but also with the development of teaching aids based on the widespread use of computer workshops, for example [9, 10], in higher and secondary educational structures.

In Table 1 columns from 1 to 5 are highlighted for transactions with annual GDP indicators, the absolute values of which are presented in column 3 (rows 1-23) at current prices for the period 19982020. A sufficiently large number of points $(n=23)$, representing statistical data, provides the completeness of the initial information. Rows 24-26 are highlighted for the possibility of forecasting until 2023 using the identified model, the calculation results for which are recorded in column 5.

Table 1. Absolute and relative statistics of GDP (in current prices), 1998-2020

\begin{tabular}{|c|c|c|c|c|}
\hline $\mathbf{N}$ & Year & GDP, billion. rub. & Relative Values of GDP rel & Polynomial Values of GDP rel \\
\hline 1 & 1998 & 2629.6 & 0.0246 & 0.0425 \\
\hline 2 & 1999 & 4823.2 & 0.0451 & 0.0435 \\
\hline 3 & 2000 & 7305.6 & 0.0683 & 0.0531 \\
\hline 4 & 2001 & 8943.6 & 0.0836 & 0.0707 \\
\hline 5 & 2002 & 10830.5 & 0.1013 & 0.0957 \\
\hline 6 & 2003 & 13208.2 & 0.1235 & 0.1275 \\
\hline 7 & 2004 & 17027.2 & 0.1592 & 0.1655 \\
\hline 8 & 2005 & 21609.8 & 0.2020 & 0.2091 \\
\hline
\end{tabular}




\begin{tabular}{|c|c|c|c|c|}
\hline 9 & 2006 & 26917.2 & 0.2516 & 0.2577 \\
\hline 10 & 2007 & 33247.5 & 0.3108 & 0.3107 \\
\hline 11 & 2008 & 41276.8 & 0.3859 & 0.3675 \\
\hline 12 & 2009 & 38807.2 & 0.3628 & 0.4275 \\
\hline 13 & 2010 & 46308.5 & 0.4329 & 0.4901 \\
\hline 14 & 2011 & 59698.1 & 0.5581 & 0.5547 \\
\hline 15 & 2012 & 66926.9 & 0.6257 & 0.6207 \\
\hline 16 & 2013 & 71016.7 & 0.6639 & 0.6875 \\
\hline 17 & 2014 & 79199.7 & 0.7404 & 0.7545 \\
\hline 18 & 2015 & 83232.6 & 0.7781 & 0.8211 \\
\hline 19 & 2016 & 85616.1 & 0.8004 & 0.8867 \\
\hline 20 & 2017 & 91843.2 & 0.8586 & 0.9507 \\
\hline 21 & 2018 & 103861.7 & 0.9710 & 1.0125 \\
\hline 22 & 2019 & 109241.5 & 1.0213 & 1.0715 \\
\hline 23 & 2020 & 106967.5 & 1 & 1.1271 \\
\hline 24 & 2021 & & & 1.1787 \\
\hline 25 & 2022 & & & 1.2257 \\
\hline 26 & 2023 & & & 1.2675 \\
\hline
\end{tabular}

Source: Compiled by the authors based on Rosstat data

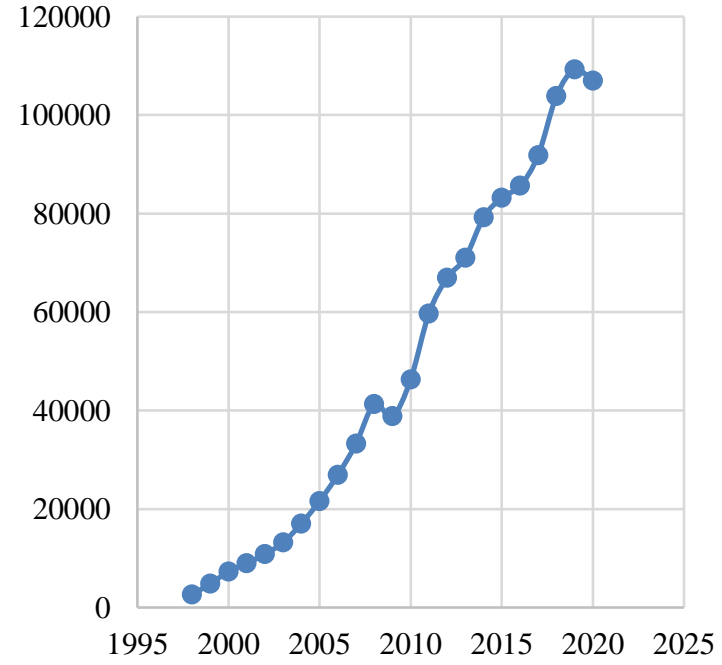

Figure 2. Dynamics of GDP, in current prices, billion rubles, 1998-2020

Source: Rosstat data
According to the Table 1 (columns 2 and 3 ) in Figure 2 it is shown a graph of changes in GDP in the period 1998-2020, which shows a decline in GDP during the 2008 crisis, a decrease in GDP growth rates from 2014 to 2016, and a fall in GDP in 2020, which began at the end Dec 2019. The nature of changes in real GDP values on the graph allows us to study the phenomena that have occurred in the economy in the period under review. The identification of statistical data of GDP can be carried out using the most frequently used functions in order to obtain a model that could be used in the problems of interpolation and extrapolation of the factors under study. To do this, we will use wellknown functions: exponential, demonstrational, logarithmic and polynomial. The results of these computational studies based on the above functions are presented in Figure 3 in the form of mathematical models indicating the corresponding coefficients of determination.

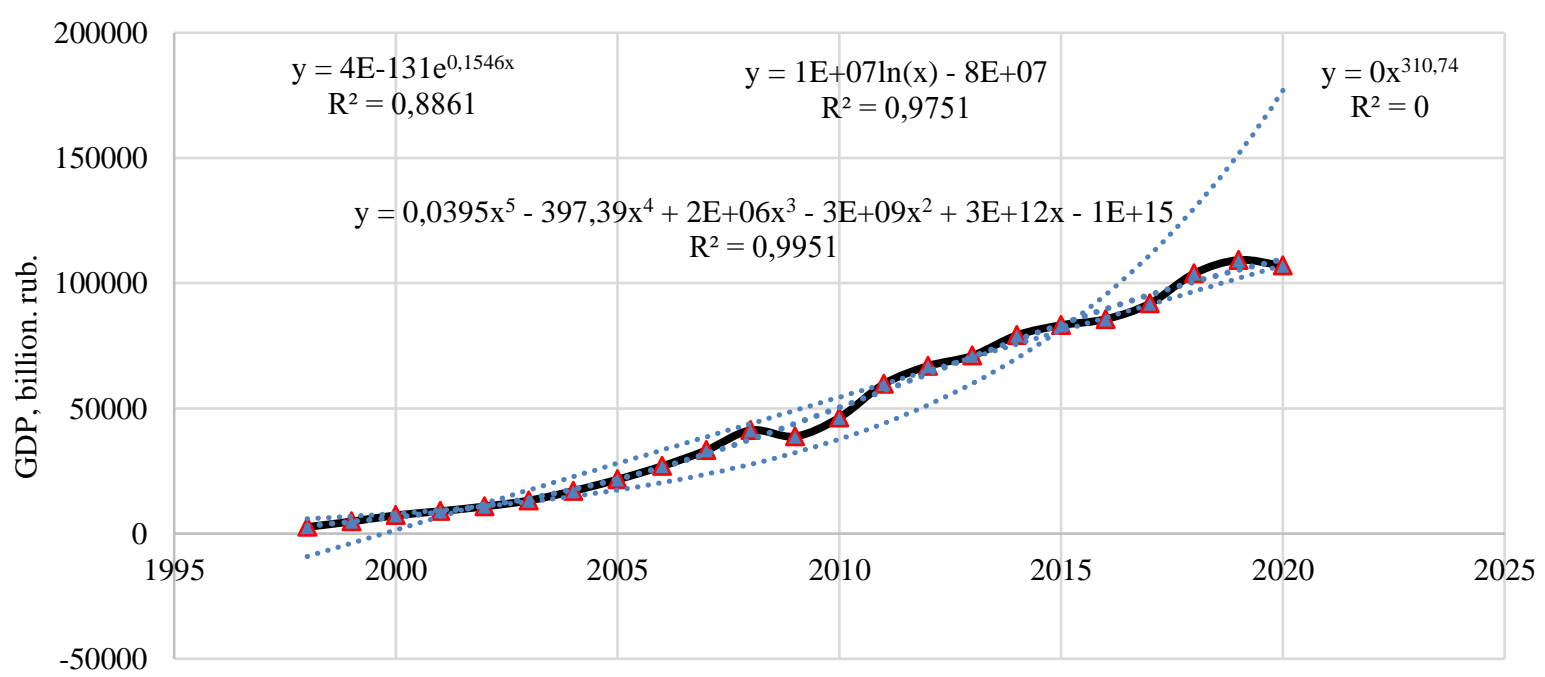

Figure 3. Identification of GDP statistics using different function classes

Source: Compiled by the authors 
Despite the rather high values of the coefficients of determination, all models in their own way reproduce the general trend of changes in GDP over time, but none of them makes it possible to identify deviations from the trend in order to assess, for example, crisis phenomena in the economy. This indicates that the investigated apparatus has a serious flaw in carrying out the interpolation procedure for the process or phenomenon under study.

\section{DISCUSSION}

It is convenient to study the possibility of extrapolation (forecasting) using models identified in a certain class of functions in relative coordinates.
At the same time, we will take GDP production in 2020 as the base value of GDP (see Table 1, column 3 , line 23). The relative values of GDPrel are presented in Table 1 in column 4.

As a result of identification, a third degree polynomial was obtained (see Figure 4) with a high coefficient of determination equal to 0.9948. Using the resulting model, we will extrapolate the theoretical values of GDPrel for 2023.

It is easy to see that during the pandemic since the end of 2019, there has been a decline in GDP production and this trend continues in the current 2021, while the theoretical time trend continues to grow despite the real situation that has arisen in both the Russian and global economies in the whole.

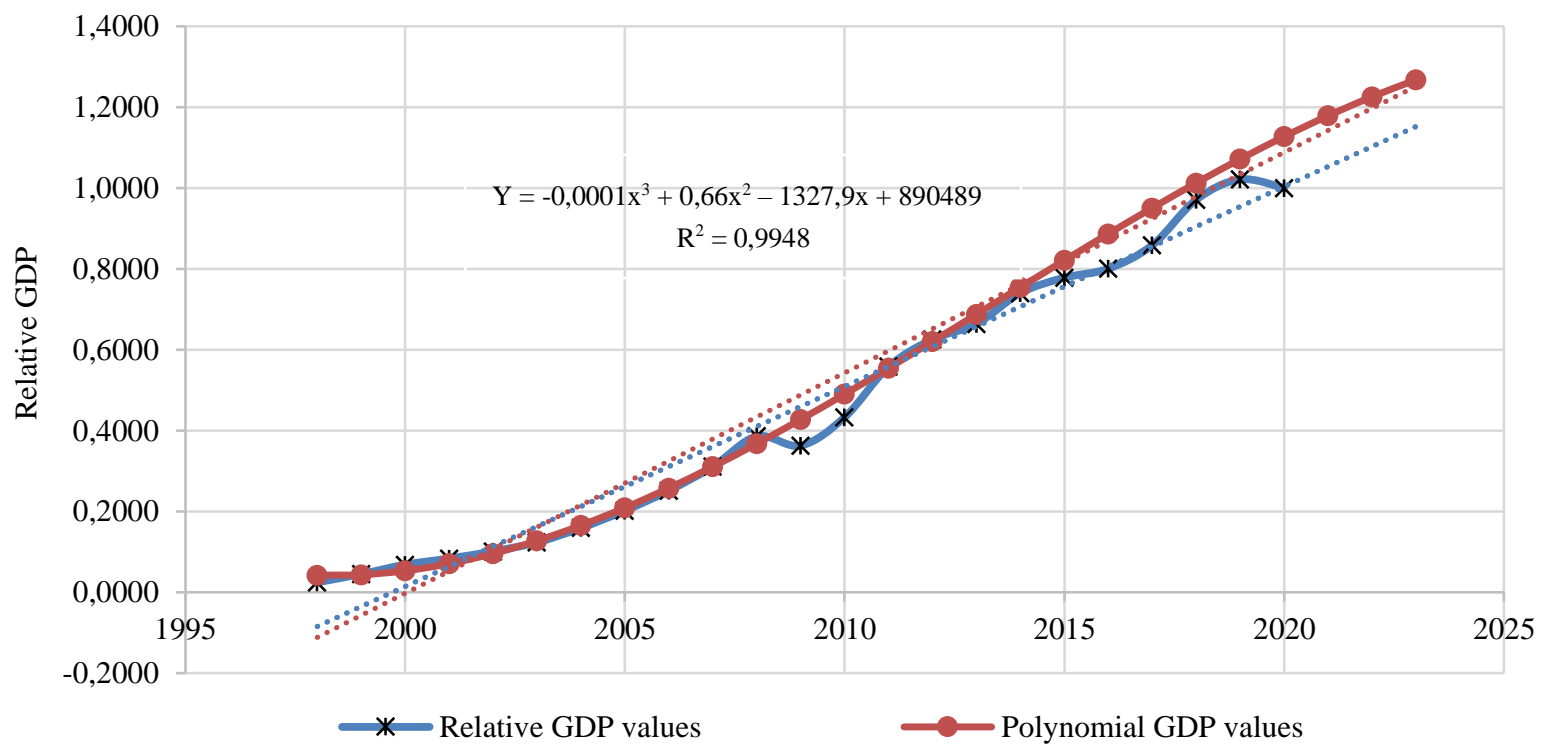

Figure 4. Extrapolation of theoretical GDP values for 2023 using a polynomial trend model Source: Compiled by the authors

A similar result can be obtained when identifying statistics and in other classes of functions.

\section{CONCLUSION}

Thus, with a sufficiently large number of points representing the statistical data of the indicator of the process under study, when identifying in the above classes of functions, the results were obtained in the form of aperiodic curves describing the corresponding trend in the indicator, which smooths out any deviations associated with changes in both internal and external factors, for example, crisis events, pandemic, etc. With an increase in the level of impacts on the system, the reliability of the results of the interpolation and extrapolation procedure using such models decreases, and especially with forecasts of varying degrees of urgency, false results can be obtained, the use of which can lead to unpredictable consequences.

As for the deviations of real GDP indicators, they depend on many factors, the main of which are noted above and in the structure of models built on the basis of known classes of functions, indicators of these factors are in principle absent. Therefore, the trend obtained with the analytical method under the conditions of changing internal and external influences cannot serve as a basis for planning the strategy of economic development.

The presented studies provide an opportunity to obtain information about the difficulty of creating an economic theory and assess the reliability of existing statistical models. Obvious ways of development of 
these scientific areas lie in the formation of a nontrivial approach to the creation of dynamic models with functional and statistical connections, allowing to solve the problem of formalization of continuously changing external and internal influences on an economic object.

\section{AUTHORS' CONTRIBUTIONS}

Nikolai T. Katanaev - head of the research team; Elena E. Alenina, Vera V. Zyulina - obtaining data for analysis, analyzing the data obtained; Mikhail A. Lastovsky - writing the text of the manuscript and its design; Ilya A. Alenin - a review of publications on the topic of the article.

\section{REFERENCES}

[1] A.A. Sozinova, S.V. Novikov, S.N. Kosnikov, G.I. Nemchenko, E.E. Alenina, "Peculiarities of Isolated Clusters Operation", International Journal of Economics and Financial Issues, 2016, vol. 6(8), pp. 19-23.

[2] N.D. Kondratyev, "The world economy and its conditions during and after the war" [Mirovoye khozyaystvo i yego kon"yunktury vo vremya i posle voyny], Vologda, 1922. (In Russ.).

[3] N.D. Kondratyev, D.I. Oparin, "Big cycles of the conjuncture: Reports and their discussion at the Institute of Economics" [Bol'shiye tsikly kon"yunktury: Doklady i ikh obsuzhdeniye v Institute ekonomiki], Moscow, 1928, 287 p. (In Russ.).

[4] J.A. Schumpeter, "Business Cycles McGrawHill Book Company", New York Toronto London: McGraw-Hill Book Company, 1939, $461 \mathrm{p}$.

[5] S.Yu. Glazyev, G.I. Mikerin, P.N. Teslya, "Long waves: scientific and technological progress and socio-economic development" [Dlinnyye volny: nauchno-tekhnicheskiy progress i sotsial'no-ekonomicheskoye razvitiye], Novosibirsk: Nauka, 1991, 224 p. (In Russ.).

[6] A.I. Shinkevich, A.A. Lubnina, N.M. Chikisheva, L.M. Simonova, E.E. Alenina, B.B. Khrustalev, R.S. Sadykova, R.R. Kharisova, "Innovative Forms of Production Organization in the Context of HighTech Meso-Economic Systems Sustainable Development", International Review of Management and Marketing, 2016, vol. 6(2), pp. 219-224. (In Russ.).

[7] A.V. Gumerov, I.V. Mukhomorova, R.R. Sadykova, L.E. Fatikhova, N.M. Chikisheva, L.M. Simonova, E.E. Alenina, "The Program "Client's Voice" as a Tool of Business Structure Innovations", Journal of Sustainable Development, 2015, vol. 8(3), pp. 263-270.

[8] A.A. Lubnina, Ch.A. Misbakhova, E.N. Arestova, V.A. Isaichev, S.G. Pavlikov, M.N. Kozin, E.E. Alenina, "Innovative Strategy for Increasing Competitiveness in Organizational Structures of Industrial Enterprises", Eurasian Journal of Analytical Chemistry, 2017, vol. 12(7b), pp. 1563-1571.

[9] V.F. Kolpakov, "Economic, mathematical and econometric modeling: Computer workshop: Textbook" [Ekonomiko-matematicheskoye i ekonometricheskoye modelirovaniye: Komp'yuternyy praktikum: Uchebnoye posobiye], Moscow: Infra M, 2018, 672 p. (In Russ.).

[10]R.S. Akhmadieva, V.M. Shinkaruk, E.V. Limarova, A.N. Rednikov, N.V. Osipova, E.E. Alenina, A.A. Pavlushin, "The new forms of environmental activeness in digital age", Ekoloji, 2019, vol. 28(107), pp. 4919-4924. 